\title{
Schopenhauer's Contraction of Reason: Clarifying Kant and Undoing German Idealism
}

SEBASTIAN GARDNER

University College London

\begin{abstract}
Schopenhauer's claim that the essence of the world consists in Wille encounters well known difficulties. Of particular importance is the conflict of this metaphysical claim with his restrictive account of conceptuality. This paper attempts to make sense of Schopenhauer's position by restoring him to the context of post-Kantian debate, with special attention to the early notebooks and Fourfold Root of the Principle of Sufficient Reason. On the reconstruction suggested here, Schopenhauer's philosophical project should be understood in light of his rejection of post-Kantian metaphilosophy and his opposition to German Idealism.
\end{abstract}

\section{The Puzzle of Schopenhauer's Kantianism}

When situating his philosophy in relation to his predecessors, Schopenhauer presents it above all in relation to - as inspired by and correcting_-Kant. ${ }^{1}$ The World as Will and Representation carries forward, Schopenhauer claims, the deepest insights of the first Critique while resolving problems that Kant left unsolved and rectifying errors concerning the role of reason and other matters, into which Kant was led by the historical accident of his proximity to Leibnizian-Wolffian scholasticism; ${ }^{2}$ at the same time, it works into the Kantian system insights from sources in ancient and Eastern philosophy to 
which Kant paid little or no attention. In the introduction to the Appendix to $W W R$ I, 'Criticism of the Kantian Philosophy', Schopenhauer writes:

[T]he whole strength and importance of Kant's teaching will become evident only in the course of time ... [I] regard Kant's works as still very new, whereas many at the present day look upon them as already antiquated. Indeed, they have discarded them as settled and done with, or, as they put it, have left them behind ... [R]eal and serious philosophy still stands where Kant left it. In any case, I cannot see that anything has been done in philosophy between him and me; I therefore take my departure from him. (WWR I, 416)

Though it is natural to read Schopenhauer in terms of a direct modification of Kant's legacy, as Schopenhauer here tells us to do, the historical fact is that by the time Schopenhauer received his philosophical education a lot of water had passed under the bridge: Schopenhauer was not a first or even second generation post-Kantian, but a latecomer. Schopenhauer nonetheless excludes from his philosophical ancestry the most prominent and philosophically spectacular of the post-Kantian developments of the age, the systems of Fichte, Schelling, and Hegel. Though constantly referring to those figures - in the most disparaging terms - Schopenhauer does not represent his own ideas as formed in reaction to the German Idealists, or allow that perception of their alleged absurdities played a role in directing him back to, as he understands it, Kantian truth. ${ }^{3}$ In our attempts to understand Schopenhauer, however, we are not bound to follow this account of the sources of his thought: Schopenhauer's demand that his ideas be measured against Kant's achievements can be honoured consistently with the attempt to understand those ideas as originally coming into existence in critical dialogue with his post-Kantian contemporaries, and there is reason for considering this a fruitful way to proceed. 
Schopenhauer's early lecture and student notebooks give evidence of his extensive exposure to and vigorous engagement with the ideas of Fichte and Schelling in the years immediately preceding the composition and publication of his first book, On the Fourfold Root of the Principle of Sufficient Reason. ${ }^{4}$ The compelling reason for ascribing a key role in Schopenhauer's development to the German Idealists lies, however, in certain well-recognized problems that his system appears to face and which appear all the more acute, the more directly we attempt to relate Schopenhauer to Kant. We can make some sense of these problems, I claim, when we understand how Schopenhauer had absorbed and taken the lesson of the two preceding decades of wrestling with the Critical philosophy and, more specifically, how he responded to and sought to invert the German Idealist systems.

Among the various inconsistencies which commentators have claimed to find in Schopenhauer's philosophy, certainly one of the most serious, and the most important for present purposes, concerns the contradiction between his identification of the Kantian thing in itself with Wille, and his account of the nature and limits of human reason. The basic problem is easily grasped. It begins with Schopenhauer's doctrine of the subservience of the intellect as such to will, ${ }^{5}$ which presents an immediate obstacle to the claim to have achieved insight into the world beyond representation. Given that the targets of the will, as we instantiate it, are exclusively worldly, how then-if the intellect serves the will — can the intellect look beyond the world as representation? That a function directly tied to objects can deploy the capacities built into in such a way as to redirect itself away from the world as representation, giving rise to the concept of something other than representation which nonetheless possesses reality, constitutes an initial difficulty. ${ }^{6}$ 
The further and greater difficulty lies in squaring Schopenhauer's claim to discursive, communicable metaphysical knowledge with the restrictive conditions he lays down on concept formation and conceptual significance. According to the account given in Fourfold Root and WWR, concepts in general are nothing but distillations from intuitive perceptual representations and, without relation to these, altogether lack cognitive value. ${ }^{7}$ Schopenhauer's assertion that willing is grasped as essentially heterogeneous with representation and its objects, entails on the face of it that volitional phenomena, though registered in conscious awareness in some fashion, cannot properly be taken up as objects of thought, i.e., that there can be no thought of oneself as a subject of willing. ${ }^{8}$ But even if this problem is set aside, the next step taken by Schopenhauer involves a difficulty which cannot be waived. Granting Schopenhauer (i) the possibility of both the concept of something beyond representation and the concept of will, and (ii) the capacity to put these two together, i.e. to think the non-representational as will, we are still missing the crucial conceptual nexus between the resulting conception of extrarepresentational Wille and the world as representation, viz., the grounding of the latter in the former. In other words, true though it may be that the 'empirical fact of a will' $(P \& P$ II, 11) that each discovers within himself, as Schopenhauer calls it, leads inexorably to the recognition that there is more to reality than is encompassed in representation, still this insight cannot, so long as Schopenhauer's strictures on conceptual significance are in place, lead to the thought that the world as representation is essentially, in its substrate, Wille, with the implication that the latter explains aspects of the constitution of the former. To put the point in Kantian language, Schopenhauer's metaphysics require that we think the world-as-will and world-as-representation in terms of the categories of respectively ground and consequent ${ }^{9}$ but if all cases of that species of relation are exhausted by the four forms detailed in Fourfold Root, each of which has an exclusively intra-representational sphere of application, then it is impossible to so much as form the thought that the world as representation is an expression of, manifest in, or in any sense conditional, dependent or supervenient on, the world as will. ${ }^{10}$ 
What renders Schopenhauer's position especially perplexing is his own repeated criticism of Kant for having made illegitimate, transcendent use of the category of causality, ${ }^{11}$ and his total rejection of the Kantian apparatus of Vernunft. ${ }^{12}$ Had Schopenhauer admitted either or both of these Kantian tenetsthat is, had he allowed a potential for non-empirical significance to the categories, and/or a native cognitive drive to grasp what does not require explanation and so is self-explanatory - then a basis for reconstructing the inference to world as Wille would be available. As things stand, it is hard to avoid the suspicion that Schopenhauer's construction of his system is guided by the very same illegitimate analogy which he finds in Kant - that he transposes an observed, empirical causal relation obtaining between one's acts of will and their effects within the world as representation, into the relation between extra-representational and representational realms. Equally, the ontological deficit which he ascribes to the world as representation-its merely illusory, unreal character, whereby a gap is created for Wille to fill-appears to take for granted a measure of reality to which his conception of cognition does not entitle him.

The issues opened up are several and complex, but let me say straightaway that, in highlighting this problem, my aim is not to convict Schopenhauer of an ultimate and irreparable inconsistency, though clearly there is scope for drawing that conclusion. My suggestion instead is that, in a spirit of interpretative charity, we should pause to consider the prima facie perplexing character of Schopenhauer's strategy. The question which needs to be addressed first of all, I suggest, is therefore this: How can it have come to seem to Schopenhauer that the metaphysical completion of Kant's philosophy could be achieved in a single innocent step, directly from the apprehension of will, without any supporting structure of the sort provided by Kant's account of the categories and the faculty of reason? 
The force of this question is underlined when we note that the relevant issue - the so-called metacritical problem, concerning the possibility of knowledge of the extra-representational conditions for representation - had been absolutely central to and endlessly discussed in the post-Kantian development ever since Reinhold, and that Schopenhauer, though entirely familiar with the various options explored by his predecessors and contemporaries, declines all those on offer.

In the first place, Schopenhauer does not have in mind a transcendental vindication of his claim concerning what lies beyond representation. What exactly transcendental modes of proof amount to is of course a vexed question, but it is generally accepted that transcendental argumentation differs from the type of metaphysical explanation which Kant calls 'dogmatic', in so far as it hinges on the discursive demonstration of an internal, synthetic connection between certain concepts or principles and the possibility of objects, underpinned by an antecedently given necessity, e.g., that of selfconsciousness. Even in establishing the sub-forms of the Principle of Sufficient Reason in Fourfold Root, which covers the territory of Kant's Transcendental Aesthetic and Analytic, Schopenhauer does not follow this pattern, and nowhere in WWR does Schopenhauer acknowledge that the relation of representation to object requires explication or needs to be treated as anything more than a case of straightforward 'correlation' (WWR I, §5). In any case, it is obvious that the inference to world-as-Wille does not have the character of Kant's Analogies and that Schopenhauer does not intend it to be understood in such terms.

Again, Schopenhauer has no sympathy with the analogue or sub-form of transcendental reasoning that Kant develops for practical reason and which finally permits cognition of the supersensible, that is, the postulates of pure practical reason. ${ }^{13} W W R$ is not, therefore, a transcendental theory of object-enabling 
theoretical presuppositions or of practically grounded postulates. A superficial comparison with Fichte makes the point vivid: whatever the similarities of their quasi-phenomenalistic treatments of empirical reality, $W W R$ has nothing in common methodologically with the Wissenschaftslehre, which takes Kant's fact of reason as axiomatic, and is preoccupied from start to finish with the problem of vindicating claims about the pre-representational structures which make natural consciousness possible. Equally obvious is Schopenhauer's remoteness from Schelling's post-Fichtean method of construction in intellectual intuition.

Nor, at the other end of the spectrum, does Schopenhauer embrace the epistemological dualism of F. H. Jacobi and J. F. Fries, the glaubensphilosophisch theists who repudiated the post-Kantian idealist development. On their account, the proper lesson to be drawn from the Critique's critique of dogmatic metaphysics and the misadventure of German Idealism is that cognition assumes essentially distinct forms, of which the understanding's grasp of empirical reality is but one, to which no priority or special privilege attaches. None of the various forms of cognition can, according to Glaubensphilosophie, be equipped with an ultimate basis in discursive proof. This rejection of rational foundations allows empirical knowledge, the Wissen achieved by Verstand, to be either, as Fries argues, paralleled by, or, as Jacobi maintains, grounded in, immediate intuitive affective cognition, the scope of which is not restricted to empirical reality. Glauben and Ahnung thus furnish claims to knowledge of the supersensible which enjoy as great a justification as empirical cognition.

This bifurcation of knowledge might seem to correspond to Schopenhauer's division of knowledge of the world as representation and as will, or at least to provide the right kind of epistemological basis for that claim, and Schopenhauer's affirmation of our capacity for a 'better consciousness' ${ }^{\text {'4 }}$ does contain an unmistakeable echo of Jacobi and Fries' epistemology. Schopenhauer's official line, however, is a 
rejection of the glaubensphilosophisch strategy. Jacobi's approach is rejected by Schopenhauer as 'illuminism' — as making metaphysical knowledge incommunicable ( $P \& P$ II, 10)—and as degrading genuine knowledge to mere faith (WWR II, 7-8), while Fries is charged with having, like the German Idealists, fabricated a power of intuiting the supersensible $\left(F R_{2}, 60-1\right)$. Both are accused of failing to see that Kant's critique denies validity to the Ideas of reason $\left(M R C D, 419-25,428-31, F R_{2}, 180-3\right)$.

An observation may now be made concerning the source of the difficulty identified in Schopenhauer. It is natural to think of Schopenhauer's system as constructed, as I have been supposing it to be, and as the Critical programme requires it to be, on the basis of a movement from within representation out to the extra-representational. Several things encourage this construal, including the order of the first two Books of WWR, Schopenhauer's insistence that WWR presupposes Fourfold Root (WWR I, xiv), and his explicit assurance that he shares Kant's starting point in 'empirical consciousness that is common to us all' $\left(P \& P\right.$ II, 6-9). ${ }^{15}$ Proceeding in this Kantian way leads however, as we have just seen, to the collision of Schopenhauer's central metaphysical claim with his restrictive account of conceptuality. It leads also, it may be added, to a puzzle concerning Schopenhauer's return to (as he understands it) Kant's idealism, given his excision of its distinctively transcendental features-making it appear as if Schopenhauer has merely conflated Kantian idealism with the dogmatic idealism of Berkeley.

It may be asked, therefore, if the reading of Schopenhauer as following through a development from immanence to transcendence tracks correctly the order of his thought. The alternative is to regard Schopenhauer's system as in part and in some sense constructed $a b$ initio from a standpoint beyond representation. This raises many new questions, but for a number of reasons, it has the ring of truth. It coheres with Schopenhauer's belief that the challenge of skepticism should be given short shrift (WWR I, 16-18, 104). Second, it agrees with the manner in which Schopenhauer sets out his idealism and 
excogitates the conditions of representation. These he presents as plain facts that can be grasped directly and apodictically, without any reflexive, perspectival, or other enabling metaphilosophical framework: Schopenhauer expects us to simply 'see', as it were, that such and such comprise the forms of representation, that there is no object without subject, and so on, as if we had an unimpeded, objective, sideways-on view of our cognitive structure and situation; as if we can just plainly represent the conditions of representation in the way that we represent objects. And it agrees, thirdly, with the recurring pattern of problematic enlargements of the picture that we encounter in the course of $W W R$, of which the discrimination of will from representation, and the identification of will with the thing in itself, are just the first two: there follow in Book III the possibility of temporary suspension of willing, and of subsistence as a pure transcendental subject of knowing, and the existence of Ideas as mediators between Wille and representation; and in Book IV, the possibility of annulling the will. In each case, Schopenhauer's addition appears to violate a necessity previously laid down, yet which he seems not to regard as requiring more than cursory justification. If, however, the appearance that Schopenhauer gives of following in Kant's methodological path is due merely to his chosen order of exposition, and the true logical order of the system presented in $W W R$ is not that of the first Critique, then we are better able to see why Schopenhauer evinces no embarrassment at what appear to be unaccountable anomalies, but rather lays claim at each point of enlargement of the picture to greater metaphysical completeness.

Of course, to repeat, problems still remain: Even if Schopenhauer does not need an account of conceptuality which shows it capable of serving as a vehicle for transcending the bounds of representation, still it must be explained how his restrictive principle of conceptual significance can avoid undercutting the basis of the system. But we would at least have made some sense of Schopenhauer's apparent indifference to the metaphilosophical issues which bother his contemporaries. 
The conjecture therefore seems worth following up. In which case, the question posed earlier can be reformulated: How did Schopenhauer come to think that philosophical thought can proceed from, and take for granted ab initio, a standpoint beyond, not merely confined within, representation?

\section{The Post-Kantian Context: Schopenhauer's Metaphilosophy}

If we are to answer this question, we need some idea of Schopenhauer's view in his earliest years of the situation of philosophy. The question points accordingly to the relevance of Fichte, Schelling, and the broader context of debate surrounding Kantian philosophy in the final decade of the eighteenth century and the first of the nineteenth. Scrutiny of the Nachlaß for the period when Schopenhauer's outlook was being formed, and of Fourfold Root, tells us a great deal concerning Schopenhauer's estimate of many individual ideas present in his philosophical environment, but it does not yield a clear-cut overall picture. Necessarily, then, any reconstruction of Schopenhauer's comprehensive view of the philosophical landscape must be tentative. What follows represents one possible account.

Let me begin with a very rapid sketch of the German philosophical scene in the first few years of the nineteenth century. It would have been clear to any non-partisan observer that Kant had succeeded in meeting the criticisms of orthodox empiricists and rationalists, whose philosophies no longer had any compelling claim to attention. However, the Critical system itself had come under intense pressure from other quarters, in particular from Schulze and Jacobi. Together, Schulze and Jacobi had showed that Kantianism fails to meet the strongest demands that could be laid upon a philosophical system, demands that, furthermore, Jacobi had famously argued, could best be met by Spinoza. The idea thus circulated that Kant's strategy to legitimate God, morality and human freedom involved a compromise of the demands of philosophical reason. The various efforts made by Kant's successors - Reinhold, J. 
S. Beck, Fichte, Schelling in his earlier period - to fortify the Critical philosophy by equipping it with secure foundations and an adequately clear and convincing methodology had come to grief: each postKantian had rapidly and in turn annulled his predecessor, or (as many judged to be the case with Fichte) had 'rescued' Kantianism only by reducing it to plain absurdity and irremediable obscurity. Again, the proposal (promoted by Niethammer) to abandon the search initiated by Reinhold for a single principle to stand at the foundation of the Kantian system, and in its place to appeal to considerations of coherence, had not borne fruit. Nor, therefore, could it even be claimed, under a modest, apologetic interpretation of Kant's aims as proceeding in the name of the gemeinen Verstand and solely with a view to its defence, that the Critical system had stabilized the convictions of natural consciousness in its own terms. The upshot that transcendental philosophy cannot supply itself with a rational foundation had in fact been affirmed, more or less explicitly, by Schelling, who in 1804 had turned away from the rationalism of transcendental philosophy and begun to seek a solution to the problem of the existence of the objective world in philosophical reinterpretations of theological doctrines. Again, the negative result was reflected in Fries' transformation of transcendental philosophy into philosophical anthropology, a move which on the surface salvaged a large quantity of Kantian apparatus, but at a more fundamental level granted victory to Jacobi, in so far as Fries emphatically denied that the facts established by transcendental analysis concern anything more than subjective necessities of representation.

Schopenhauer conducted a thorough review of this legacy. ${ }^{16}$ The view to which he was drawn, I suggest, is that there is no prospect of meeting the demand that the Kantian system of idealism ground itself in the manner envisaged by Reinhold and Fichte. In other words, the requisite agreement between the first-order claims of the system, and the basis on which it claims to know these, cannot be demonstrated. At first blush this purely negative result might sound like no conclusion at all, or so 
pronouncedly skeptical as to provide no positive basis for Schopenhauer's metaphysical project. There is however a way forward from this point which accords well with Schopenhauer's purposes. If philosophy cannot rationalize its own claims to cognition, then either this failure puts an immediate and total end to the philosophical endeavour, or it may be taken to license a return to innocence, a resumption of the task of philosophy under the naive heading of simply describing how the world appears on the face of it to be and the forms which appear to constitute the conditions of our cognition. And because Schopenhauer considers the face of the world, its physiognomy, to be transparent in its cognitive structure and pregnant with metaphysical significance, he regards the first option as arbitrary and the second as adequately motivated. This allows it to be understood how skepticism regarding the post-Kantian metaphilosophical project could lend succour and encouragement to a non-skeptical postKantian metaphysical project.

The key features of Schopenhauer's response to the post-Kantian metaphilosophical impasse are as follows. In the first place, the negative conclusion that transcendental philosophy cannot ground itself can be taken as a datum carrying metaphysical significance. If insight into the grounds of our claims to knowledge cannot be got, and if this fact cannot be rationalized in Kant's fashion, i.e., attributed to the constitutive limitations of our mode of cognition, then the only alternative is that it must be laid at the door of reality itself, i.e., regarded as a reflection of the order of things (or the absence thereof). In other words, the situation of finding oneself as a knowing subject, one's existence as such, should be interpreted as a non-rational matter not in the weak, merely epistemological sense (affirmed by Kant) that our cognition is subject to inherent limitations which prevent it from becoming fully transparent to itself, but in the strong, metaphysical sense that there could not be a reason in the order of things for the existence or possibility of cognition. ${ }^{17}$ Acceptance of cognition as ultimately unaccountable distinguishes Schopenhauer's response to the metaphilosophical impasse from those of Jacobi and the 
later Schelling, both of whom, though each convinced in their own way that rational foundations are unavailable at the outer limit of reflection, nonetheless persevere in attempting to rationalize cognition, in an indirect fashion, by embedding human cognition within an encompassing teleological structure. For Jacobi, this consists in our interpersonal relation to God, and for Schelling, in the human subject's participation in a process of divine self-illumination. Schopenhauer's rejection of any such oblique rational foundation for cognition is, I will argue in the following section, clear from the Fourfold Root.

Second, Schopenhauer's rejection of metaphilosophical concerns helps it to be understood why he does not regard transcendence of representation as a problem requiring its own special solution. The transcendentalist assumption is that cognition is confined originally within the circle of representations, and that the task is accordingly to locate grounds within representation for claims concerning their objective reference. For Kant, Reinhold, and Fichte, the entire argument for transcendental idealismthe reason why there can be an argument for it, and why transcendental ideality is not simply a given metaphysical fact of the order of 'esse is percipi' - is interdependent with this restrictive assumption; so too is the possibility of discursive transcendental proof of the a priori conditions of objects of experience. The assumption can be disposed of, however, the moment the meta-critical task is abandoned. The point, therefore, is not that, with the post-Kantian metaphilosophical problem shelved, we are thereupon entitled to claim access to the perspective of the Absolute, as per Schelling's identity philosophy, but merely that there is no longer any reason for thinking that some special difficulty is involved in grasping a metaphysical reality beyond representation. The way is paved for Schopenhauer's non-transcendental assertions of idealism, and of the reality of Wille, as matters of plain metaphysical fact. 
Schopenhauer's commitment to, as it might be put, metaphilosophical naivety- his view that epistemological and metaphysical facts can be grasped through direct apprehension and obtain without any constructive activity on our part-is made clear in notes on Kant:

Nothing can be demonstrated a priori, but many things can only be seen and grasped a priori, in that they cannot be seen and grasped in any other way than by the mental faculty to which they appertain ... - Proof is required only by that which is not directly seen and grasped $a$ priori and is therefore logically traced back to something else. — To make the a priori knowable the object of the faculty of reason is all that is necessary for science, and this consists in our presenting it clearly and definitely in an abstract expression; it is then a judgement of metaphysical or metalogical truth. (MRCD, 335-6)

Schopenhauer's claims that there is no object without subject and vice versa, and that the form of our cognition and the constitution of objects is spatio-temporal and causal, proceed on this basis. We should not, therefore, be misled by the fact that Schopenhauer talks in $W W R$ as if the fundamental problems of transcendental philosophy — establishing the transcendental ideality of the objects of knowledge and a priori conditions of cognition — had blindingly simple solutions which the postKantian development beginning with Reinhold had perversely chosen to ignore, into thinking that Schopenhauer has failed to understand what is at issue in the transcendental project. Rather his underlying view, developed in the light of his evaluation of the post-Kantian development, is that it is in the nature of cognition that the only 'solutions' which the transcendental problems allow of take the form of an appeal to a direct 'seeing and grasping' of a priori necessities. The de jure and de facto questions concerning human knowledge which Kant had separated out are thus collapsed into one another: both are answered in the same breath and at a single stroke. Though well aware that, by 
transcendentalist lights, such justification is so shallow as to not deserve the name, Schopenhauer's contention is that nothing more is available. ${ }^{18}$ As he at one point puts it: 'there is really no knowledge of the principles that form the basis of all knowledge'; 'there is no knowledge of knowledge' (MRCD, $453-4){ }^{19}$

What, however, of our knowledge that underlying the realm of representation lies Wille?

Schopenhauer's solution to the problem of how Wille can be conceived to be the ground of the world of representation shares the same form. Just as a priori matters concerning the world as representation are, as Schopenhauer puts it, given directly 'by the mental faculty to which they appertain', so similarly the fact that Wille underlies representation is given directly by the fact of the instantiation in us, qua agents, of Wille. This metaphysical knowledge is not achieved, therefore, by means of an inference in the strict, rule-governed sense. There is indeed a transition in thought from (i) the recognition of the 'empirical fact' ( $P \& P$ II, 11) of one's own willing and of its heterogeneity with representation, to (ii) the realization that Wille is the stuff of reality, but the former is not an epistemic reason for the latter. The transition is instead both spontaneous and impressed on us: the metaphysical state of affairs consisting in the existence of Wille itself directly produces in us knowledge of itself. It expresses itself in our cognition. And when we subsequently reflect on our capacities for knowledge in general—all reflection being bound to the forms of the world as representation-it is a foregone conclusion that we are unable to discover anything in the nature of conceptuality that would allow us to explain how we come into possession of this piece of metaphysical knowledge. So our insight into the world's substrate of Wille, though conceptually articulated, involves a use of concepts, or mode of thinking, which we cannot elucidate. In terms of the Kantian transcendental programme, this claim to knowledge breaks every rule in the book, but in the context of the metaphilosophical outlook I have attributed to Schopenhauer, it can be defended: if we could identify intellectual operations whereby the thought that 
the world is in essence Wille is formed and in virtue of which it is justified, then the insight would be annulled; but since the insight is in fact given to us, the falsity of the antecedent can be inferred. The inconsistency between Schopenhauer's claim to metaphysical knowledge and his theory of concepts therefore remains formally unresolved, but it does not undermine the system, because the system tells us that the formal inconsistency is necessitated by how things are metaphysically. Schopenhauer's commitment to this thoroughly non-Kantian view will become clearer in the next section.

\section{On the Fourfold Root of the Principle of Sufficient Reason}

I hope to have made it convincing that Schopenhauer's return to Kant is conditioned by factors in the post-Kantian environment, attention to which allows us to see that Schopenhauer's metaphysics involve more than a simple (mis-)reading of Kant's idealism as Berkeleyan and a refusal to acknowledge its properly transcendental character. In this section I want to support the attribution to Schopenhauer of the metaphilosophical position described above by looking at the key moves made in Fourfold Root. ${ }^{20}$

The reasons why Schopenhauer saw fit to make the Principle of Sufficient Reason the topic of his doctoral dissertation and first published philosophical work are not immediately obvious. Explicit discussion of the principle had faded out of philosophical writing in the post-Kantian period after J. A.

Eberhard's unsuccessful attempt to reinstate it. ${ }^{21}$ It is also true, however, that the question of what to make of PSR, what stand to take on its validity and implications, is implicitly at issue throughout the German Idealist development. As Kant had left matters, the cognitive significance of the principle is captured in two ways: first, in the causal principle of the Second Analogy, and second, in reason's principle concerning the givenness of the unconditioned, the proper value of which lies in regulative 
employment of the Ideas of reason. ${ }^{22}$ The development from Fichte onwards, however, with its demands for systematic completeness, reasserts the ineluctability and authority of PSR for philosophical reflection, albeit not under that description: the ontologically formulated claim of early modern rationalism, that for everything that is, or is not, there must be a reason, reappeared in the form of the metaphilosophical claim that philosophy must assume a fully systematic form and that the uniquely valid system of philosophy must be 'all of one piece'. ${ }^{23}$

Schopenhauer's decision to broach the topic of PSR explicitly, thereby reviving a philosophical term with Wolffian-Leibnizian associations, reflects his appreciation of the German Idealists' tacit restoration of PSR as the supreme principle of philosophical reflection. ${ }^{24}$ The driving thought behind Fourfold Root, I suggest, is that Kant's partial deflation of PSR had left the job only half done. ${ }^{25}$ In Schopenhauer's eyes, by granting the principle its intrinsic rational authority and merely contesting its serviceability for human cognitive purposes, Kant had left PSR very much intact; and once the appeals to the inherent limitations of the human mode of cognition, and to modesty of philosophical aspiration, which stabilized Kant's position, had been judged unsatisfactory, it was inevitable that PSR would burst upon the scene once again, as it clearly had in the projects of Fichte and Schelling. Extirpation of PSR consequently demanded a more thorough deconstructive treatment. ${ }^{26}$

Though the ultimate implication of the account given in Fourfold Root is to dethrone PSR once and for all, the work presents itself in a different guise, namely as a regrounding of PSR, an analytical exercise in disambiguation of its sub-forms, and a systematization of epistemology. The tension between the officially (re)constructive and unofficially deconstructive agendas of the work is reflected in Schopenhauer's equivocation concerning the existence, or not, of PSR as a genuinely unitary single principle. 
On the one hand, the four principles discriminated - the laws of (i) causality, (ii) connection of concepts and judgements, (iii) spatio-temporal ordering, and (iv) motivation-are described by Schopenhauer as 'different applications' of the same principle, which he says carries a 'general meaning', viz., that 'always and everywhere each thing exists by virtue of another thing' $\left(F R_{2}, 2,232\right)$. The four laws are said to spring from 'one and the same original quality of our whole cognitive faculty as their common root', which comprises 'the innermost germ' of the world as representation $\left(F R_{2}\right.$, $232)$, 'the sole principle and sole support of all necessity' $\left(F R_{2}, 225\right)$. Elsewhere Schopenhauer talks of 'one ground or reason presenting itself in a fourfold aspect, which I call figuratively a fourfold root' $\left(F R_{2}, 162-3\right)$. An overhauled, post-Kantian version of PSR would thus seem to have been provided. ${ }^{27}$

On the other hand, with equal definiteness, Schopenhauer states that in each of its four applications PSR has 'a different meaning', indicating 'its origin from different powers of the mind': PSR 'does not issue directly from one kind of knowledge but primarily from different kinds in our mind'; it is 'as multiple as the sources of the principle' $\left(F R_{1}, 2 ; F R_{2}, 2-4\right)$; it is merely 'a common expression for four entirely different relations each of which rests on a particular law that is given a priori' $\left(F R_{2}, 231\right) .{ }^{28}$ There is no justification for speaking of an 'absolute ground or reason' or 'ground in general' $\left(F R_{2}\right.$, 234).

Schopenhauer's vacillation between a model in which four laws share a single root, and one in which PSR reduces to a fourfold conjunction of principles, each with their own separate root, is presented by him as a matter of seeking to fulfil Kant's two desiderata for systematicity, the laws of homogeneity and specificity: the law of homogeneity directs us to bring the objects of knowledge under a common concept, and the law of specificity to differentiate them; so we are quite appropriately pulled in two 
directions $\left(F R_{2}, 1-3,231-2\right) .{ }^{29}$ This disguises rather than rationalizes the tension, however, and when the specific implications of Schopenhauer's disentangling of the four forms of PSR are examined, it becomes clear that the four-root model wins out. The decisive points are the following.

1. Each of the four laws is defined by Schopenhauer with respect to a different domain of objects: (i) changes in real objects, ${ }^{30}$ (ii) judgements, (iii) parts of space and time, and (iv) actions. It is crucial that the intelligibility of each law is grasped in and through, and is inseparable from, the kind of object over which it ranges. A sufficient understanding of each law is secured by an understanding of the nature of the species of object to which it applies. ${ }^{31}$ Given the metaphysical heterogeneity of the four domains, it follows that the different senses in which each law tells us that an object A can be a reason for an object B, or put differently that the question 'Why B?' can be answered by reference to A, are wholly independent of one another. The term 'reason for' emerges therefore as a place-holder for 'either (i) an efficient cause, or (ii) a ground of judgement, or (iii) an instance of the mutual conditioning either of the parts of space (i.e. geometrical necessity) or of the moments of time, or (iv) a motive'.

2. This renders it analytic that each domain of objects is subject to the appropriate law, for each law simply reduces to the assertion that there is a domain of objects of a certain kind which exist in and by virtue of their being related in certain ways to one another. Affirming that a certain domain of objects is subject to PSR is strictly equivalent to asserting that there exists a unified manifold of a certain type and that the mode of being of its elements is relational. The only 'general meaning' which can be attached to PSR over and above the conjunction of the four laws is therefore simply the higher order information that (a) the four laws all have it in common that they range over homogeneous and mutually discrete manifolds of objects; (b) the objects in each domain exist only relationally within those manifolds; (c) no objects are possible outside the domains of the four laws; (d) the four domains 
jointly constitute the world as representation. ${ }^{32}$ In this way, Schopenhauer draws PSR into the closest possible connection with idealism: the thesis of the world's ideality, and PSR, are equivalent; PSR says no more than that objects are cognitively conditioned.

3. The reduction of PSR to a mere aggregate of principles, each of which merely defines a type of relational existent, allows Schopenhauer to 'internalize' PSR, that is, to identify reason outright with a set of structures internal to representation and without conceivable significance outside that context. If we were able to grasp a common meaning to 'reason' as it operates in the four different contexts, this meaning could be projected onwards, making it possible to raise the question of the reason for the existence of the world as representation and our cognition of it; it would have to be admitted as thinkable that the world stands in relation to something else as being 'in virtue of' it and that cognition has roots in reality. Schopenhauer's reduction instead makes cognition inexplicable: PSR 'cannot be applied to the totality of existing things, to the world, including the intellect in which the world presents itself' $\left(F R_{2}, 232\right.$; emphasis added). Similarly, the impossibility of giving a proof of PSRwhich a rationalist unconvinced by Wolff's attempt to derive it from Principle of Contradiction would take as evidence of its epistemological primitiveness and inherence in the very fabric of being, i.e., understand realistically_-becomes in Schopenhauer a reflection of its dissociation from reality. ${ }^{33}$

4. The decomposition of PSR into four laws allows Schopenhauer to wipe out the distinction between levels of reason vital for Kant and the German Idealists, that is, their distinction between the lower level of reason embodied in empirical reality, and the higher form of reason affirmed in Kant's practical cognition of the supersensible, Fichte's Wissenschaftslehre, Schelling constructions in intellectual intuition, and Hegel's speculative logic. ${ }^{34}$ 
5. Of particular importance is the distinction and independence from one another of the first and second forms of PSR. By differentiating PSR as the principle of efficient causality from PSR as the principle of relations of judgements, Schopenhauer is not making the anodyne point that efficient causality and inference are conceptually different relations, nor is he simply alerting us to the danger of confounding the two. Schopenhauer does frequently charge philosophers with having confused reasons in the sense of efficient causes with reasons in the sense of logical grounds-instances are cited throughout Fourfold Root - but drawing attention to this distinction is nothing new: Kant is fully appreciative of it, even in his pre-Critical writings, and deployment of it in criticism of rationalism goes back to Crusius. That Schopenhauer has more in mind - that he means to deepen the gulf between the order of things and the order of ideas, in a way that goes beyond Kant and in fact recalls Hume's bifurcation of relations of ideas and matters of fact—-follows from his claim that failure to properly separate efficient causality from inference is directly responsible for the cosmological and ontological arguments $\left(F R_{2}\right.$, 14-16, 228-9). ${ }^{35}$ In order for his diagnosis that the crux of rational theology is a confusion of different forms of PSR to make sense, Schopenhauer must be interpreted as rejecting the most minimal assumption of a correspondence between the order of thought and that of things: his challenge to rational theology thus lies at an even deeper level than Kant's Dialectic; Kant does not, and would not be prepared to, dispute the formal validity of rational theology on the same grounds. Given his view of the mutual indifference of the orders of efficient causality and thought, Schopenhauer is right to complain that Kant confuses different senses of 'reason' (WWR I, 457): the idea driving Kant's analysis of empirical reality is that it must exhibit the form of a set of intelligibly interrelated rules, and this internal connection between thought and physical reality, a tenet of rationalism which Kant believes must be preserved in order for Hume's challenge to be met, is repudiated by Schopenhauer. ${ }^{36}$ 
6. The equivalence of PSR with the principle of the world's ideality lays the ground for the identification in WWR of the substrate of the world with Wille. If the being of objects consists in relational existence in accordance with the four laws of PSR, then the world as representation and all of its contents are non-substantial. ${ }^{37}$ The non-substantiality of the world as representation thus follows from the consideration that its ground is nothing but PSR, which is itself without any ontological character, ${ }^{38}$ and hence incapable of bestowing substantiality. What transforms our knowledge of the non-substantial character of the world as representation into the realization of its positively illusory character is acquaintance with Wille-awareness of which provides the measure of reality in light of which the non-substantiality of the objects of representation is grasped as an ontological deficiency. There is therefore a deep connection of the possibility of cognition, not just with the ideality of its objects, but also with their unreality.

Finally, it is helpful to review the differences in the treatment of PSR in Kant, German Idealism, and Schopenhauer, with reference to Spinoza. ${ }^{39}$

Anxiety surrounding Spinoza's anti-theistic necessitarianism had of course a long history in early modern philosophy. Its 'nihilistic' implications, and the interdependence of these with the rigorous application of PSR, had been emphasized by Jacobi. Kant accepts this view: as he explains in the second Critique, unconstrained application of PSR — which cannot be avoided if empirical objects are things in themselves - destroys the concept of human freedom, which provides the foundation of morality, teleology, and personal deity (1996: 220-1; Critique of Practical Reason, 5.100-2). Whence the necessity of transcendental idealism, which provides the only means of shielding the convictions of the gemeinen Menschenverstand from the destructive force of PSR. While granting the necessary and inescapable character of PSR for the faculty of reason, Kant splits its rational force, which is on the one 
hand channelled into the structure of experience and incorporated by the understanding - in the form of the principle of causality, and the regulative principle of seeking the conditions of all conditionedsand on the other deflected out into the abyss that lies beyond the land of truth. In $\S \S 76-7$ of the third Critique, Kant seeks to deepen the gulf between Spinozism and transcendental idealism: knowledge of things in themselves presupposes intellectual intuition, and intellectual intuition, he argues, cancels all distinction between the possible and the actual, and between Ought and Is; those distinctions presuppose a discursive, non-intuitive intellect, and transcendental idealism explains how the world must be for such an intellect. Spinoza is thus correct, Kant allows, in supposing that reality qua totality of things in themselves exhibits absolute necessity; but he is wrong to suppose that such a reality comprises the object of human knowledge. Human freedom, and all that depends on it, is thus made possible by the fact that empirical reality conforms to PSR only in a qualified, relatively weak sense.

The German Idealists, sharing the aim of refuting nihilism but regarding Kant's suspension of PSR as providing at best only a temporary reprieve for human freedom, find it necessary to revise Kant's strategy. In Fichte, the revision takes the form of an attempt to meet Spinozism on its own terms, and in Schelling and Hegel, of a fusion of Kant with Spinoza. In both Fichte's intensified transcendental idealism and Schelling and Hegel's absolute idealism, PSR is expanded out, allowing the totality of what exists and can be known to fall within and fill out the space of reasons, as in Spinoza, but without nihilistic implications. This demands extensive remodelling of the concept of a reason and hence of PSR: ${ }^{40}$ what counts as 'sufficient reason' is something other than what is considered to do so by our common understanding, with the consequence that reality as conceived in the metaphysics of German Idealism, in accordance with reason in its higher form, appears to natural consciousness, which is acquainted only with the lower form of reason, Verstand, as an 'inverted world', eine verkehrte Welt (Schelling and Hegel 2000: 283). 
Schopenhauer's treatment of PSR agrees with the German Idealists that rendering Kant consistent requires re-engagement with the principle, and a less equivocal account than Kant's, but goes in precisely the opposite direction: Schopenhauer contracts the space of reasons, setting it in contradistinction to Wille. This is explained by the fact that Schopenhauer's aim is to secure the 'nihilistic' implications of Spinozism — its anti-theism, determinism, rejection of teleology, broadly materialist orientation, and primarily naturalistic view of human motivation. ${ }^{41}$ Spinoza's 'nihilistic' conclusions are regrounded by Schopenhauer in such a way that they derive not, as in Spinoza, from PSR itself, but from the fact of its ideality, that is, from the impossibility of subsuming reality under it. ${ }^{42}$ What makes this necessary_or, from another angle, what precipitates the metaphysical insight which takes us from Spinoza's rationalism to the anti-rationalist neo-Spinozism of $W W R$-is the German Idealist demonstration that PSR can be twisted into a shape that allows it to rebut Spinozistic nihilism. For all Schopenhauer's deprecations of the German Idealists, he took their project sufficiently seriously for it to have profoundly shaped his own. The world as Wille is no less of a Verkehrung, albeit of a very different sort, of the world given to natural consciousness, and in that regard Schopenhauer stands alongside the German Idealists, in opposition to Kant.

\section{Against metaphysical optimism}

Let me conclude by first summarizing the argument in this paper, and then adding one final interpretative proposal concerning Schopenhauer's philosophical motivation.

Beginning with a familiar puzzle that arises when Schopenhauer is viewed in direct relation to Kant, I suggested that progress can be made if Schopenhauer's return to Kant is viewed as mediated by his 
negative assessment of the metacritical component of the post-Kantian development, a contention for which the notebooks provide clear evidence. The mediation consists more precisely in Schopenhauer's extraction of two things from the (in his eyes) historically demonstrated impossibility of constructing a self-grounding version of the Kantian system: (a) an entitlement to abandon the epistemological task central to Kant's transcendental philosophy, thereby relieving metaphysics of the burden of accounting for its own claims to knowledge in the demanding terms insisted on by Kant and the German Idealists; and (b) the additional inference that PSR, and reason as such, is confined to the interior of cognition in the way explained in Fourfold Root.

Both moves are radical, so much so that it may be asked whether they are really justified. Do they not represent over-reactions to the plight of post-Kantian metaphilosophy? The charge might stick if Schopenhauer were merely stepping into the negative space left by the perceived failure of the metacritical project, but this is not the full story. What Schopenhauer takes to positively justify his innovations is his opposition to metaphysical optimism. This is the other major element that conditions and is essential to the explanation of his return to Kant. As remarked earlier, the physiognomy of the world is for Schopenhauer rich with metaphysical significance, and on his account, no undeluded apprehension of the world can fail to see in it a scene of 'incurable suffering and endless misery', 'the battle-ground of tormented and agonized beings who continue to exist only by each devouring the other' (WWR I, 411; II, 581). This axiological insight is Schopenhauer's fundamental principle of philosophical reflection, ${ }^{43}$ and it conditions his early reception of the post-Kantian development: because he rejects in advance the axiological conclusions of the German Idealists and Glaubensphilosophen, Schopenhauer is disposed to fault the reasoning adduced to support those conclusions. Metaphysical pessimism is the premise from which Schopenhauer derives the necessity of deconstructing PSR. 
The scope of Schopenhauer's rejection of optimism is of course very much broader than Fichte, Schelling, and Hegel, but it is in the systems of Fichte and Schelling that Schopenhauer in his earliest years finds the most advanced modern expression of the Leibnizian standpoint, accompanied by the most pernicious distortions of Kant's insights. ${ }^{44}$ Schopenhauer is thus able to draw an analogy of his own destructive treatment of German Idealism, with Kant's destruction of the Leibnizian-Wolffian system (WWR I, 510-11). ${ }^{45}$

That Schopenhauer does not present his system as formed in reaction to German Idealism is not hard to understand: presenting $W W R$ instead as a direct step forward from Kant constitutes a strategically effective means to undercut and sweep away the accumulated post-Kantian debris. An unfortunate consequence of this strategy, however, is that it allows Schopenhauer to seem merely a pre-Critical dogmatist, who has failed to take the transcendental lesson and whose extra-representational metaphysics is undermined by his intra-representational theory of concepts. This impression is corrected, I have suggested, by restoring Schopenhauer to the full post-Kantian context: Schopenhauer goes back to Kant and revises him in the way that he does, specifically in order to contradict the metaphysical optimism which he sees flowering in German Idealism, and on the (contestable but far from arbitrary) basis (first) that no other post-Kantian development can claim superiority in articulating Kant's insights, and (second) that the axiological quality of the world provides sufficient testimony that it is not the unfolding of the mind of God. 


\section{References}

Allison, Henry (1973) The Kant-Eberhard Controversy: An English Translation together with

Supplementary Materials and a Historical-Analytic Introduction of Immanuel Kant's On a Discovery

According to Which Any New Critique of Pure Reason Has Been Made Superfluous by an Earlier One.

Baltimore, MD: Johns Hopkins University Press.

Fichte, Johann Gottlieb (1982), Foundations of the Entire Science of Knowledge (1794-95). In The

Science of Knowledge, with the First and Second Introductions, ed. and trans. Peter Heath and John

Lachs (Cambridge: Cambridge University Press), pp. 87-286.

Fichte, Johann Gottlieb (1988) Concerning the Concept of the Wissenschaftslehre (1794). In Early

Philosophical Writings, trans. and ed. Daniel Breazeale (Ithaca, NY: Cornell University Press), pp. 87135.

Fichte, Johann Gottlieb (1994) '[First] introduction to the Wissenschaftslehre' (1797). In Introductions to the Wissenschaftslehre and Other Writings (1797-1800), trans. and ed. Daniel Breazeale (Indianapolis: Hackett), pp. 2-35.

Franks, Paul (2005) All or Nothing: Systematicity, Transcendental Arguments, and Skepticism in German Idealism. Cambridge, Mass.: Harvard University Press.

Fries, Jakob Friedrich (1798) 'Über das Verhältniss der empirischen Psychologie zur Metaphysik’. Psychologisches Magazin, 3, 156-20.

Kant, Immanuel (1996) Practical Philosophy, trans. and ed. Mary Gregor, intro. Allen Wood. Cambridge: Cambridge University Press.

Longuenesse, Béatrice (2005) 'Kant's deconstruction of the principle of sufficient reason'. In Kant on the Human Standpoint (Cambridge: Cambridge University Press), pp. 117-42. 
Schelling, Friedrich Wilhelm Joseph von (1980) Of the I as Principle of Philosophy, or On the Unconditional in Human Knowledge (1795). In The Unconditional in Human Knowledge: Four Early Essays 1794-1796, ed. Fritz Marti (Lewisburg: Bucknell University Press), pp. 59-149.

Schelling, Friedrich Wilhelm Joseph von, and Hegel, Georg Wilhelm Friedrich (2000) 'The Critical Journal, Introduction: On the essence of philosophical criticism generally, and its relationship to the present state of philosophy' (1802), trans. H. S. Harris. In George di Giovanni and H. S. Harris (eds.), Between Kant and Hegel: Texts in the Development of Post-Kantian Idealism (Indianapolis: Hackett), pp. $272-310$.

Schopenhauer, Arthur (1969) The World as Will and Representation, 2 vols., trans. E. F. J. Payne. New York: Dover.

Schopenhauer, Arthur (1974) On the Fourfold Root of the Principal Sufficient Reason, 2nd edn. (1847), trans. E. F. J. Payne. LaSalle, Illinois: Open Court.

Schopenhauer, Arthur (1974) Parerga and Paralipomena: Short Philosophical Essays, 2 vols., trans. E. F. J. Payne. Oxford: Clarendon.

Schopenhauer, Arthur (1986) Vorlesung über die gesammte Philosophie d.i. Die Lehre vom Wesen der Welt und von dem menschlichen Geiste. In vier Theilen. Erster Theil: Theorie des gesammten Vorstellen, Denkens und Erkennens (1820), in Theorie des gesammten Vorstellens, Denkens und Erkennens. Aus dem handschriftlichen Nachlaß, hrsg. u. eingeleitet von Volker Spierling. München: Piper.

Schopenhauer, Arthur (1988) Manuscript Remains: Critical Debates (1809-1818), ed. Arthur Hübscher, trans. E. F. J. Payne, Manuscript Remains in Four Volumes, vol. 2. New York: Berg. Schopenhauer, Arthur (1997) On the Fourfold Root of the Principal Sufficient Reason, 1st edn. (1813), in F. C. White, Schopenhauer's Early Fourfold Root: Translation and Commentary. Avebury: Ashgate. 
White, F. C. (1992) On Schopenhauer's Fourfold Root of the Principle of Sufficient Reason. Leiden: E. J. Brill.

\section{Notes}

${ }^{1}$ Works by Schopenhauer cited, with abbreviations used, are: The Fourfold Root of the Principal Sufficient Reason, 1st edn., 1813 (FR $)$, and 2nd edn., $1847\left(F R_{2}\right)$; Manuscript Remains, vol. II, Critical Debates (MRCD); Parerga and Paralipomena (P\&P); Vorlesung über die gesammte Philosophie $(V g P)$; and The World as Will and Representation $(W W R)$. For bibliographical details, see References.

${ }^{2}$ See $M R C D, 310, W W R$ I, 418, II, 582. Scholasticism is, for Schopenhauer, a large historical category: it denotes 'the whole period beginning with Augustine, the Church Father, and ending just before Kant', its chief characteristic being 'guardianship of the prevailing national religion over philosophy' (WWR I, 422); it 'depends entirely on positive Jewish-Christian dogmatics' (MRCD, 476).

${ }^{3}$ Compare Fries, who explicitly develops his own position and return to Kant alongside a detailed critique of post-Kantian idealism; see for example Fries 1798.

${ }^{4}$ These writings are collected in $M R C D$.

${ }^{5}$ E.g. $P \& P$ II, 97: 'we could say also that the intellect is physical, not metaphysical ... it has sprung from the will, belonging to it as the objectification thereof'.

${ }^{6}$ Which Schopenhauer attempts to meet by appeal to a 'free surplus' of intellect, exhibited in 'genius' $(P \& P$ II, 97).

${ }^{7}$ See, e.g., $F R_{2}, 15,146-8, W W R$ I, 39-42, and MRCD, 298-9, 468, 471. Schopenhauer's account recalls strongly Berkeley's (and Hume's) critique of abstract ideas; the essential difference being that the data from which abstraction is made, in Schopenhauer, comprises not mere sensation, purely sensible 'ideas', but what Schopenhauer calls intuitive perceptions, intrinsically representational subjective contents. 
${ }^{8}$ A different problem, note, from the one that Schopenhauer admits as an incomprehensible 'miracle of miracles' $\left(F R_{1}, 53, F R_{2}, 211-12\right)$, which is the identity of the subjects of knowing and of willing. ${ }^{9}$ Schopenhauer himself puts it thus in WWR II, 642. Note that the problem is not resolved, but is merely confirmed, by the claim that in awareness of action and its motivation we enjoy an inside view of efficient causality and of bodily objectification of willing $\left(F R_{2}, 212-14, W W R\right.$ I, $\left.\S \S 18-22\right)$, even when this is coupled with the confession of ignorance regarding its 'miraculous' character; for the problem is precisely how it is possible for those relations to be thought. There is of course also an issue concerning the application to Wille of the concept of existence or being, which Schopenhauer restricts to the context of representation (e.g. $M R C D, 342,346-7,421, F R_{2}, 226$ ), but its well-known peculiarities make it advisable not to put weight on it and to focus instead on the difficulties arising from the concept of causality.

${ }^{10}$ Compare $\mathrm{FR}_{2}, 232-3$ : 'what holds good of world merely in consequence of those very forms [of phenomena; laws of our intellect], cannot be applied to the world itself, in other words, to the thing-initself that manifests itself in the world. And so we cannot say that "the world and all things therein exist by virtue of something else"; such a proposition is simply the cosmological proof.' And $P \& P$ II, 94-5: 'The inner essence of things is foreign to the principle of sufficient reason; it is the thing-in-itself and this is pure will. It is because it wills, and it wills because it is. It is that which is absolutely real in every being.' The problem is at the surface in the final chapter of WWR II. Here Schopenhauer says both that '[a]fter all my explanations, it can still be asked, from what this will has sprung' and so forth, and that such questions, 'or rather the answers to them, are transcendent, that is to say, they cannot be thought by means of the forms and functions of our intellect' (WWR II, 640; emphasis added). Thus when Schopenhauer writes, 'I start from experience and the natural self-consciousness given to everyone, and lead to the will alone as what is metaphysical' (WWR II, 643), the question is: Even before we come to ultimate matters, if explanation, Erklärung, as such is a relation that can hold only 
between representations (as affirmed at $W W R \mathrm{I}, 80$ ), then how can we in the first place be led out from the physical to the metaphysical? If the forms of thought are utterly alien to the 'inner being-in-itself' of things (for the reason that this is 'not an intellect, but something without knowledge'), then in what sense can Schopenhauer claim to have 'deciphered' the world as representation, supplied 'the key to the inner nature of the world' (WWR II, 642)? (The explanatory character of metaphysical knowledge reappears, note, in Schopenhauer's doctrine of intelligible character: $P \& P$ II, 92 makes this explicit.) In an earlier chapter, where he raises the question 'how a science drawn from experience can lead beyond it', Schopenhauer says that his metaphysics pursues, in place of pre-Kantian dogmatics, the alternative path of deciphering the 'cryptograph', Geheimschrift, of experience, and talks of experience as a whole as 'being interpreted, explained from itself', 'aus sich selbst gedeutet, ausgelegt' (WWR II, 182); but avoidance of the word erklären, and the muting of metaphysical explanation into a softer, hermeneutical form of throwing light on matters, does not avoid the problem, which reveals itself in all its clarity and acuteness when Schopenhauer goes on to say that 'the actual, positive solution to the riddle of the world must be something that the human intellect is wholly incapable of grasping and conceiving' (WWR II, 185). The puzzle, in short, is Schopenhauer's confidence that there is - that there can be thought to be-any 'riddle' at all. (An unshakeable conviction of his: the notion that the world has 'merely a physical' significance is described as 'the most deplorable error that has sprung from the greatest perversity of the mind', $P \& P$ II, 102.)

${ }^{11}$ E.g., $F R_{1}, 68, F R_{2}, 233-4, M R C D, 294,309,312-13,328-9,478-8, W W R$ I, 435-6, 447.

${ }^{12}$ Reflected in Schopenhauer's treatment of Kant's antinomies, the theses of which are rejected as false (MRCD, 480-9, and WWR I, 493-501). Schopenhauer's critique of Kant's conception of Vernunft is found in MRCD, 304-6, 336-7, 474-6, and WWR I, 480-5.

${ }^{13} P \& P$ I, 110-11 and 117 gives Schopenhauer's estimate of Kant's moral theology; see also $M R C D$, $316, F R_{2}, 176-7$, and Schopenhauer's critical comments on G. E. Schulze's moral theology in $M R C D$, 
11-12. Kant's differentiation of (pure) practical from theoretical reason is rejected in $M R C D, 337-8$, WWR I, 522-3, and $V g P, 418-20$.

${ }^{14}$ See $M R C D, 295,320,323-5,430-1$. The state of mind is associated strongly by Schopenhauer with aesthetic experience.

${ }^{15}$ Again: Schopenhauer claims that he 'arrives at no conclusions as to what exists beyond possible experience, but furnishes merely an explanation and interpretation of what is given in the external world and in self-consciousness' (WWR II, 640).

${ }^{16}$ Schopenhauer's notebooks and annotations to lecture notes from the period 1809-18, published in $M R C D$, register his acceptance of the key points concerning the fate of Kant's philosophy and the shortcomings of Kant's successors.

${ }^{17}$ In order to appreciate the force of this denial, one may compare Fichte's view, as recounted in Schopenhauer's lecture notes: Fichte defines exactly the sense of 'reason or ground of knowing' which Schopenhauer rejects $(M R C D, 20-28,70)$. In so far as it can be said that cognition exists for the sake of Wille's self-annulment, this thought — which may occasionally seem to surface in Schopenhauer, and which his follower, Eduard von Hartmann, makes much of — finds its place only within the world as representation, from which it draws its limited truth. Thus when Schopenhauer writes that 'Nature leads the will to light', and that cognition emerges 'in order that it [Wille] can recognize or know its own nature' (WWR I, 400), the 'sake' or Wozu in question is only in a virtual sense that of Wille. The situation here is thus not essentially different from how it is with Schopenhauer's treatment of natural teleology in general, or with his conceptions of 'eternal justice' and the 'moral tendency' of the world, which are relativized to 'the phenomenal appearance of the will' (WWR II, 591; at greater length, WWR I, 350-4).

${ }^{18}$ One important aspect of this is Schopenhauer's denial that PSR has application to the subject-object relation itself; PSR obtains only between objects. See $W W R$ I, §5: 'no relation according to the 
principle of sufficient reason subsists between subject and object' (13); 'a demand for a ground of knowledge has no validity and no meaning here' (15). Fichte is cited as having made the mistake of attempting to ground the object on the subject (WWR I, 13).

${ }^{19}$ The denial of knowledge-of-knowledge here, note, derives from reflection on the epistemological order of justification, and is to be distinguished from (though of course it coheres with) the identically formulated conclusion that 'there is no knowledge of knowing' in $F R_{2}, 208$, which derives from the impossibility of the subject's self-objectification.

${ }^{20}$ For commentary on this work, see White 1992.

${ }^{21}$ See Allison 1973.

${ }^{22}$ On Kant's Critical treatment of PSR, see Longuenesse 2005.

${ }^{23}$ As an index of the restoration of PSR, see Schelling's interpretation of Kant as relying on PSR no less than Leibniz in order to make the transition from the unconditioned to the conditioned (Schelling 1980: 120).

${ }^{24}$ And their covert revival of theological forms of argument, albeit to non-theistic conclusions: the cosmological and ontological arguments.

${ }^{25}$ Schopenhauer in fact regards Kant as having failed to liberate himself from PSR (MRCD, 463n), and lays at his door responsibility for the German Idealist development, be it only because he made it so easy for his teachings to be misinterpreted $\left(F R_{2}, 164,176\right.$; also $M R C D, 64,412$, and $\left.V g P, 252-4\right)$. Fichte is explicitly charged in WWR I, 32-4, with having failed to grasp the teaching of the first Critique and having continued, like the dogmatists, to mistake PSR for an 'aeterna veritas'; Fichte confused its different forms in making his claims regarding the absolute I, and his philosophy is, according to Schopenhauer, simply the opposite of the old materialism (which in fact contains more truth: WWR II, 13). 
${ }^{26}$ See MRCD, 337, regarding Schelling and Kant's common error. The second edition of Fourfold Root gives a clearer view of its destructive intention, in part due to the repeated interpolation of critical references to Fichte and Schelling, but there can be little doubt that Schopenhauer in 1847 is simply spelling out what had been in his mind in 1813 but which it had been better, at that early point in his career, to leave unsaid.

${ }^{27}$ In $V d G, 443-5$, Schopenhauer affirms explicitly that there is a 'Grundform' of the PSR, and that it refers to a single type of 'Verbindung' of objects, and that its various sub-forms share 'eine gemeinschaftliche Eigenschaft'. At the same time, it is asserted that PSR appears in 'ganz verschiedenen Gestalten', with 'verschiedene Bedeutungen'.

${ }^{28}$ WWR I, 456: 'In my essay on this principle, I showed in 1813 that it has four entirely different meanings, and that in each of these it originates primarily from a different faculty of knowledge.' ${ }^{29}$ The analogy thereby implied is indicative of Schopenhauer's attitude to epistemology, for these two laws are envisaged by Kant —as the passage from Kant quoted in $F R_{2}, 3$, indicates—as relating to bodies of empirical knowledge.

${ }^{30}$ More exactly, grounds of becoming in empirical objects, 'the appearance and disappearance of states in time' $\left(F R_{2}, 53-5\right)$.

${ }^{31}$ Exactly this is said in $F R_{2}, 209-10$, in connection with our knowledge of the subject's various powers.

${ }^{32} \mathrm{PSR}$ in its general significance is, as Schopenhauer describes it, a 'metalogical' truth $\left(F R_{2}, 161-3\right)$; 'In consequence of the Kantian philosophy, it [PRS] is no longer an aeterna veritas, but merely the form, i.e. the function, of our intellect' (WWR II, 641).

${ }^{33} \mathrm{FR}_{2}, 32-3,229, W W R$ I, 73, and $V g P, 444$ : PSR is the principle of all explanation, and so cannot itself be explained. 'What is most certain yet everywhere inexplicable is the content of the principle of sufficient reason' (WWR I, 73). Note that there is also a question as to whether PSR can be ascribed 
truth. In Fourfold Root, Schopenhauer talks of it as having truth (e.g., $\left.F R_{2}, 161\right)$, but in a passage from the notebooks he outlines a cogent alternative: 'Now as truth belongs solely to knowledge and the understanding is the truth-giving principle, it is the principle of principles', and 'there is really no knowledge of the principles that form the basis of all knowledge' (MRCD, 453-4).

${ }^{34}$ Schopenhauer has of course further, more focussed objections to these; for example, he also objects that Kant's differentiation of practical from theoretical reason is, in Kant's own terms, unjustified (WWR I, 522-3). But the basic levelling work is done in Fourfold Root.

${ }^{35}$ Schopenhauer refers to the arguments as they appear in Descartes, Anselm, Schelling, and Hegel. Spinoza is later indicted on the same grounds, and again Schelling is represented as a modern recapitulation of the same errors $\left(F R_{2}, 16-22\right)$. The kinship of Fichte's reasoning with 'Onto-theology' is noted in $M R C D, 111$.

${ }^{36}$ It is worth noting that at one place in Fourfold Root Schopenhauer evinces concern that he has separated the laws too far from one another, making our success in reasoning about real things a matter of 'chance' $\left(F R_{2}, 162-3\right)$. There is in fact, I suggest, scope for Kant to object that Schopenhauer's treatment of PSR allows Hume's problem to reappear.

${ }^{37}$ The root of PSR is thus the essential 'Dependenz, Instabilität, Relativität und Endlichkeit' of our objects $(\operatorname{VgP}, 445)$, the fact that no object can ever be taken as 'etwas schlechthin für sich bestehendes, Unabhängiges, oder auch etwas Einzelnes, Abgerissenes' $(V g P, 444)$. The form of our cognition-its 'in virtue of', the fact that its objects allow themselves to be explained at all—is an index of the failure of each individual item of knowledge to achieve substantiality. The existence of the world as representation is, Schopenhauer says, shown in Fourfold Root to be merely 'relative' (WWR I, 6): 'the whole world exists only in consequence of and in conformity to it [PSR], as its corollary so to speak' (WWR I, xiv). As regards Kant's category of substance, as employed in empirical judgement, this is 
dissolved by Schopenhauer into the concept of 'matter', which in turn reduces to causality ( $W W R \mathrm{I}$, 458, 471-2, $\left.M R C D, 478, F R_{2}, 67,118-19\right)$.

${ }^{38}$ It is merely expression of necessity: 'The principle of sufficient reason is just the expression [Ausdruck] of this necessity of a reason or ground' $\left(F R_{2}, 33\right)$.

${ }^{39}$ Franks 2005 provides an outstanding account of the complex relations of Kant and German Idealism to Spinoza and PSR.

${ }^{40}$ See Fichte's reconstrual and employment of PSR in 1988: 132, 1982: 111, 120, and 1994: 26. Note that what Fichte calls der logische Satz des Grundes (1982: 111), of which he says that it has merely restricted validity, does not correspond to PSR in its full meaning, for this Satz is itself referred to an unconditioned ground to which nothing is opposed (viz., the absolute self); the logische Satz des Grundes_PSR in Fichte's narrow sense - comes into play only when there exists opposition. It is Fichte's commitment to PSR in its full, broad meaning that Schopenhauer targets.

${ }^{41}$ It does not follow from this that Schopenhauer himself attaches these theses primarily to Spinoza or identifies himself as a 'Spinozist', any more than he dubs his own metaphysics nihilistic. Schopenhauer allies himself on some points with Spinoza (e.g., WWR I, 126, 422n; II, 13, 337), and recognizes that Spinoza is no optimist (WWR II, 171), but more often treats him as an adversary, intimating his acceptance of the contemporary idealist rehabilitation of Spinoza (e.g., WWR I, 86-7; II, 87, 170-1, 357, 577, 590, 642). This comes with some qualification, however: remarks at WWR II, 350 and 645 casts doubt on the German Idealist appropriation, and Schopenhauer concludes $W W R$ with the avowal that his system is related to Spinoza's as the New Testament is to the Old (WWR II, 644-6).

${ }^{42}$ Intriguingly, the sections from the Critique of the Power of Judgement referred to above, which were of huge inspirational value for the German Idealists due to the account they give of the intuitive intellect as a higher form of reason, are also seized on by Schopenhauer, who says of $\S 76$ that it contains 'the pith of the Kantian philosophy': see $M R C D, 326-7$. Schopenhauer, it may be presumed, 
interprets Kant's account of the loss of distinction in the supersensible, and the relativity of human reason, as a warrant for the identification of world with Wille.

${ }^{43}$ In Schopenhauer's essay discussing man's need for metaphysics, its proximate source is identified as 'astonishment' at the existence of the world and oneself, a theoretical matter, but its 'more specific character' is said to spring obviously from 'the sight of the evil and wickedness in the world' (WWR II, 171). The priority of the axiological is asserted again and in the clearest terms at WWR II, 579: 'If the world were not something that, practically expressed, ought not to be, it would not also be theoretically a problem.'

44 'Pantheism ... is essentially optimism' (WWR II, 644), and 'is wholly untenable in face of that evil side of the world' (WWR II, 591).

45 That Schopenhauer regards Schelling and Hegel as a recrudescence of early modern rationalism, and understands his own role accordingly as a (higher) repetition of Kant's destruction of rationalist metaphysics, is clear from, for example, $F R_{2}, \S \S 7-8,13-23$. It should be noted, however, that Schopenhauer also finds in Fichte and Schelling (but not Hegel) some of the materials with which to construct an antithetical, anti-optimistic idealist system: hence the kinship of Schopenhauer's concept of Wille with Fichte's Trieb, and of the structure of Schopenhauer's metaphysics with the speculations of Schelling after his abandonment of the identity philosophy in 1804. Exploration of Schopenhauer's debts to the German Idealists is a topic for another occasion. One issue deserving particular consideration is the relation between Schopenhauer's view of the incapacity of German Idealism to accommodate evil, and Schelling's attempt in his 1809 essay On the Essence of Human Freedom (a work well known to Schopenhauer: $M R C D, 353)$ to show that, to the contrary, the problem of accounting for human moral evil can be met through a modification of the idealist system. 